\title{
Is body image associated with perseverance? A study among people with normal and increased body weight
}

This article was published in the following Dove Press journal: Psychology Research and Behavior Management

\author{
Wojciech Styk $\mathbb{D}^{\prime}$ \\ Szymon Zmorzyński (iD ${ }^{2}$ \\ Waldemar Klinkosz (iD) ${ }^{3}$ \\ 'Institute of Psychology, Faculty of Social \\ Sciences, The John Paul II Catholic \\ University of Lublin, Lublin, Poland; \\ ${ }^{2}$ Department of Cancer Genetics with \\ Cytogenetic Laboratory, Medical \\ University of Lublin, Lublin, Poland; \\ ${ }^{3}$ Institute of Psychology, Faculty of \\ Christian Philosophy, Cardinal Stefan \\ Wyszynski University in Warsaw, \\ Warsaw, Poland
}

Background: The extreme lack of perseverance in obese and overweight people is mainly associated with difficulties in holding back irrelevant thoughts or memories. The aim of this study was to analyze the relationship between body image and perseverance.

Methods: The research was carried out amongst a cohort of 135 people with normal and overweight/obese body weight. The criterion determining body image in the study participants was an index in the form of a subjective assessment of body weight (too low/correct/ too high). Perseverance was determined using a website with simple maze tasks. For the assessment of one's nutritional status, the applied body mass index (BMI) was utilized. For the statistical analysis, the Student's $t$-test and the r-Pearson correlation were used.

Results: Respondents with a normal BMI were more persistent in performing the tasks, in comparison with those who possessed a BMI above the normal range. There was a positive correlation between the average time spent on one task and the BMI. People in either group of normal BMI or with an overweight BMI, who assessed their body weight as too high, had lower results of analyzed perseverance indicators than those who assessed their body weight as normal.

Conclusion: This is the first study analyzing the relationship between body image with perseverance. Our results showed that perseverance is associated with body image. There was a correlation between the distractor resistance index and BMI. Lower results of analyzed perseverance indexes were observed in people perceiving their body weight as too high and not necessarily overweight.

Keywords: body image, perseverance, overweight, obesity, BMI, stereotypes

\section{Plain language summary}

Motivation for change and perseverance are the main factors in achieving set goals. Our research indicates that persistence deficits may be associated with being overweight obese or the possession of an eating disorder. Another important psychological factor is the subjective body image of people affected by these diseases. The aim of our study was to analyze the relationship between the subject's assessment of their own weight and perseverance. The respondents were divided into three groups: normal, too high and too low body weight according to their self-assessment. People who assessed their body weight as too high had significantly lower perseverance than those with assessed normal body weight. Our results indicate the relationship of perseverance with body image. In people who are overweight or obese, attention should be first paid to their subjective perception of their body. Applied therapies should be focused on self-esteem improvement as these techniques may help to increase one's perseverance, and this is an important factor in their treatment.
Correspondence: Wojciech Styk Institute of Psychology, The John Paul I Catholic University of Lublin, Al. Raclawickie 14, Lublin 20-950, Poland $\mathrm{Tel}+4878 \quad 1222630$

Email wojciech.styk@gmail.com 


\section{Introduction}

Nowadays, nutritional temptations may appear anywhere, but not everyone faces the same difficulties in regard to regulating the amount of food consumed or resisting food temptations. Therefore, the question arises as to what then decides about overweight and obesity? How do overweight people differ from the others in the population? Are these factors only biological (e.g. reduced thermogenesis) or sociocultural (e.g. low socioeconomic status)? Moreover, psychological factors have a considerable impact. ${ }^{1}$ They may include perseverance. The studies using self-description questionnaires and psychological tasks have shown that perseverance as a component of impulsiveness contributes to the development and maintenance of obesity. ${ }^{2,3}$

Obesity and overweight can be associated with low self-esteem. ${ }^{4}$ In recent years, many studies have been devoted to the coexistence of obesity and overweight with symptoms of depression and depressed mood. ${ }^{5-7}$ This phenomenon has brought more attention to the development of methods that may help people struggling with obesity and overweightness. The lack of perseverance in obese and overweight people has been associated with the difficulty in inhibiting irrelevant thoughts or memories. This may result in overweight people having difficulty in controlling thoughts about eating and/or their negative body image. ${ }^{3}$ This phenomenon can lead to overeating because thoughts about eating increase the willingness to eat. $^{2,8}$

The research by Engel et al has shown that focusing on the body image and concerning its shape (dysfunctional cognitive strategy) increased such concerns. ${ }^{9}$ One's body image plays an essential role in the development of the spectrum of eating disorders. ${ }^{10}$ Studies carried out in many countries describe the relationship between cultural factors, i.e. the "thin ideal" and its internalization and dissatisfaction with one's body. It is now being accepted that dissatisfaction with one's own body is an important risk factor for the development of eating disorders. ${ }^{10,11}$

Overweight or obese people are commonly subjected to inescapable weight-related social discrimination and are often stereotyped as unattractive, lazy and not persistent, immoral and dishonest. ${ }^{12}$ Individuals can internalize this stigma by accepting these beliefs, engaging in self-devaluation and holding weight-related self-stigmatizing attitudes. ${ }^{13}$ Weight self-stigma is related to dissatisfaction of body image. ${ }^{14}$ Negative body image can be associated with a range of negative outcomes including poor psychological functioning, e.g. low persistence. ${ }^{12,14,15}$

\section{The current study}

In the psychological and medical literature, there are a few studies on the association of the body image with perseverance. Some studies are focused on the search for the relationship between perseverance, overweight and obesity, ${ }^{3}$ whilst other studies have been devoted to techniques to enhance perseverance and improve effectiveness in weight loss processes, such as mental simulations. ${ }^{16-18}$ The aim of this study was to find a relationship between body image and perseverance as an important factor in achieving one's set goals. In the analysis of current research in this field, we suppose that there ought to be a correlation of body image with perseverance. Negative stereotypes associated with a lack of perseverance in overweight and obese people might be internalized by individuals possessing negative body image with this in turn influencing negatively on their perseverance.

\section{Methods}

\section{Participants}

Participants in the study were recruited through a dedicated website which was made specifically for the purpose of this study. The website address was provided publicly through social networking sites. The instruction for study participants contained the information about limitations. In the study cohort, healthy participants who were not in the treatment and/or on diet were included.

The condition for participation in the study was the consent to conduct the study, seeing as a lack of consent made it impossible to move to other screens containing the study.

The study was completed by 135 people, $64 \%$ of them were women $(n=87)$. The average age of the subjects was 32 years, with the age range 19-50 years. Most of the subjects had a higher education degree $(82 \%)$. The average body weight of the individuals was $68.89 \mathrm{~kg}$, with the range 43-102 kg. According to body mass index (BMI), 15 subjects $(11 \%)$ had a lowered body weight, 84 people $(62 \%)$ had normal body weight, while 36 people $(27 \%)$ had excessive body weight. Moreover, the cohort estimated, by subjective assessment, their own body weight - 6 people (4\%) assessed it as too low, 81 people $(60 \%)$ as normal, and 48 $(36 \%)$ as too high. The BMI of those subjects who assessed their weight as too low was on average $\mathrm{M}=19.34 \pm 2.04$; 
Table I The groups' structure of respondents

\begin{tabular}{|l|l|l|l|l|}
\hline & \multicolumn{3}{|l|}{ Subjective body weight assessment } & \multirow{2}{*}{ All } \\
\cline { 1 - 4 } BMI & Too low* & Normal & Too high & \\
\hline$<18.5 *$ & $3(20 \%)$ & $12(80 \%)$ & - & $15(100 \%)$ \\
$18.5-24.99$ & $3(4 \%)$ & $57(68 \%)$ & $24(28 \%)$ & $84(100 \%)$ \\
$>24.99$ & - & $12(34 \%)$ & $24(66 \%)$ & $36(100 \%)$ \\
\hline
\end{tabular}

Note: *This group was not analyzed due to low numbers.

Abbreviation: BMI, body mass index.

those who assessed it as normal $\mathrm{M}=21.39 \pm 2.94$ and those who assessed it as excessive $\mathrm{M}=25.84 \pm 4.89$. The characteristics of the participants are mentioned in Table 1.

\section{Measures}

\section{Procedure}

The website contained a note about the research authors, the purpose of the study and a brief description of the procedure. Each individual was informed clicking the "Next" button participation in the study was accepted. The first stage was to complete a survey on sex, age, education, body weight and height. The subjects were also asked to evaluate their body weight (too low/normal/too high). At the second stage, instructions were given for tasks, which consisted of solving a series of simple mazes and the subjects were required to solve as many maze tasks as possible, without any time limit. The solution of a maze lies in marking with the pointer the path from the green point "entrance" to the red point "exit", by avoiding the black "walls". An example of the maze task is shown in Figure 1. The software did not allow the passage through inner "walls" of the maze. The number of attempts to move from the "entrance" to the "exit" of the maze was unlimited - it was important to reach the goal, i.e. the

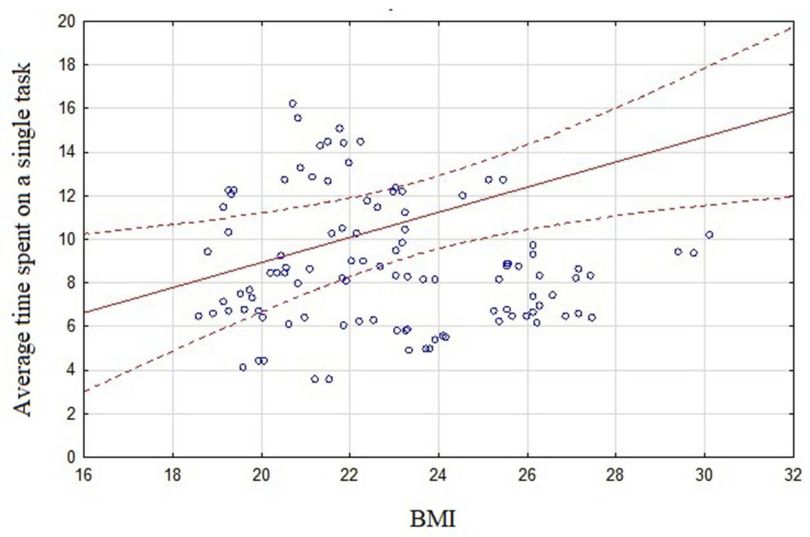

Figure I Correlation between BMI and average time spent on a single task $r=0.244 ; p<0.05$. "passage" through the maze. Before the series of proper mazes, the participant had the opportunity to pass a trial maze. A single maze task was displayed one by one. The passage through the maze resulted in the presentation of another randomly allocated maze. The individual had the ability to quit the task at any time by clicking the "Quit" button. At the end of each task, a screen "thank you for participating in the study" was displayed.

\section{Perseverance}

To measure perseverance, the Simple Maze Test was used. ${ }^{19}$ The measurement of perseverance was determined by completing the repetitive tasks. ${ }^{20-22}$ These studies were based on the determination of perseverance as the ability to overcome the discomfort resulting from the desire to abandon an action, overcoming obstacles such as distractors and uncontrollable thoughts distracting from the action and the ability to control the taking of substitute activities. The Simple Maze Test allows the determination of two perseverance indicators. The first is the number of maze tasks solved - a perseverance indicator, that takes into account the efficiency of task solving. In this task, there is no negative stimulus associated with failure - the maze tasks were selected so as to be easy.

Easy tasks are those in which $80 \%$ of the subjects achieved the correctness of the result reaching not less than $80 \%$, while difficult tasks are such conditions in which $80 \%$ of people achieved correctness not higher than $25 \%{ }^{21}$

The second indicator is the time spent on solving the tasks - an indicator that does not take into account the efficiency of solving the tasks, only the time spent on completing a task.

Research using this test showed that the persistence measured by these two indicators is a construct conditioned by personality (indicators of perseverance positively correlate with conscientiousness and self-control) and situational (the positive effect of mental simulations on persistence). ${ }^{19}$

The Simple Maze Test also determines the average time spent on a single task. This auxiliary indicator was calculated as the quotient of the time spent on a task and the number of tasks solved. This indicator does not describe the persistence of the subjects, but determines the focus on the task, resistance to distractors and the ability to inhibit irrelevant thoughts or memories. The tasks were easy and did not require a long thought process to solve them. It was assumed that high values of this 
indicator arise when the subjects are not focused enough on the task to hand and are subjected to activities or thoughts that distract them from the task being performed. Low values of this indicator will appear when the subjects work without distraction from the task - they will have the ability to stop irrelevant thoughts and/or the resistance to distractors.

\section{$\mathrm{BMI}$}

BMI is a correlation coefficient containing a quotient of the weight and square of height for the assessment of the correctness of nutritional status. According to the WHO, in adults, the category overweight is diagnosed at BMI of $25-29.9 \mathrm{~kg} / \mathrm{m}^{2}$ and obesity at BMI $\geq 30.0 \mathrm{~kg} / \mathrm{m}^{2}$. At normal weight, $\mathrm{BMI}$ is in the range $18.5-24.99 \mathrm{~kg} / \mathrm{m}^{2}$. Underweight is diagnosed when BMI is below $18.5 \mathrm{~kg} / \mathrm{m}^{2}{ }^{23}$ The BMI of the study participants was calculated basing on the weight and height values declared in the surveys.

\section{Subjective body weight assessment}

Body image is one's perceptions and attitudes in relation to one's own physical characteristic, such as weight, shape, height and skin color. ${ }^{24}$ This is a multidimensional construct that incorporates cognitive, affective, behavioral and perceptual facets. Negative body image is defined as negative subjective evaluations of one's physical body including body weight. ${ }^{25}$ In our study, one dimension of the simple body image assessment was applied - subjective body weight assessment. Before the main task was solved, each individual answered the question "my body weight is...", which was listed on the dedicated website. The subjects responded by selecting one answer of the following: too low; correct, too high, assessing their body image.

\section{Data analysis}

Data analysis showed that all included variables had a normal distribution. Dependent variables did not take values below or above the three SDs. Thus, no corrections were made. The groups did not differ significantly at levels of the variables, which suggests that, as a result of randomization, equivalent groups were formed. Based on the empirical data collected, groups were distinguished according to the BMI value. These groups were as follows: individuals with normal body weight ( $\mathrm{N}=84$, BMI: 18.5-24.99), and those with weight above the norm $(\mathrm{N}=36, \mathrm{BMI}>24.99)$. The analysis of the group with a reduced BMI was omitted due to the small sample size $(\mathrm{N}=15)$. Other groups were distinguished according to the subjective assessment of weight and they included those who defined their own body weight as normal $(\mathrm{N}=81)$ and those recognizing the weight of their body as excessive $(\mathrm{N}=48)$. As previously mentioned, subjects who defined their own body weight as to low $(\mathrm{N}=6)$ were omitted due to the small group of respondents (See Table 1).

For statistical analyses, the Student's $t$-test and the r-Pearson correlation analysis were used. The calculations were made using the Statistica version 13 software.

\section{Results}

\section{Perseverance as a function of BMI}

The individuals with a normal BMI solved almost double the amount of maze tasks $(\mathrm{M}=79.9 ; \mathrm{SD}=83.7)$ in comparison to the subjects with BMI above normal $(\mathrm{M}=46.9 ; \quad \mathrm{SD}=40.3)$. A similar relationship was observed in the case of the time spent on the whole task; the subjects with normal BMI range spent much more time on the whole task than those with higher values BMI. These differences were statistically significant $(p=0.03)$. Differences in the average time spent on a single maze task were also statistically significant $(p=0.01)$. The subjects with normal BMI needed much less time for one task $(\mathrm{M}=9.8 ; \mathrm{SD}=4.1)$ than the subjects in the group of BMI above normal $(\mathrm{M}=16.1 ; \mathrm{SD}=19.5)$. The r-Pearson correlation analysis showed a significant correlation between the average time spent on solving the task and BMI ( $\mathrm{r}=0.244 ; p<0.05$; see Figure 2). Other perseverance indicators, i.e. the number of tasks performed and the time spent on tasks, did not demonstrate significant correlations with BMI.

The differences observed in groups with normal and higher BMI turned out to be statistically significant. For these comparisons, Cohen's $d$ was in the range of $0.45-0.50$. The observed effect size was classed as a medium. ${ }^{26}$ Particular

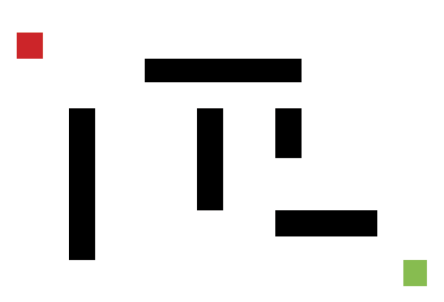

Figure 2 An example of a maze task. 


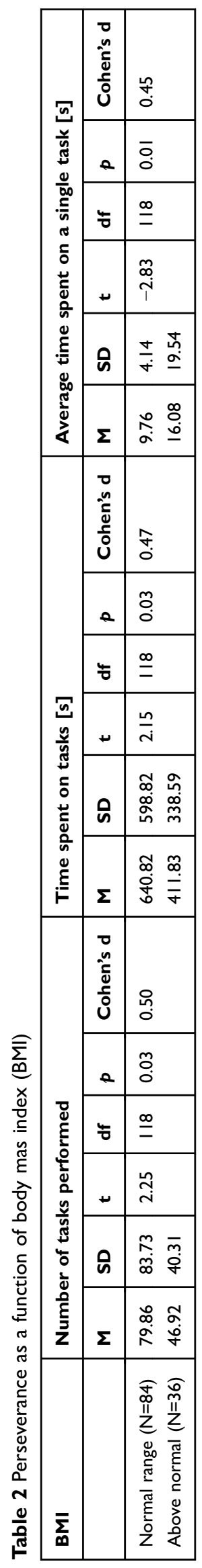

results of these two groups and the results of the Student's $t$-analysis is presented in Table 2 .

\section{Perseverance as a function of subjective assessment of body weight of subjects with normal BMI}

The subjects with normal BMI, depending on their selfassessment of body weight, differed significantly from one another in regard to the number of maze tasks completed and the average time spent on the task. The results of the group with normal BMI are presented in Table 3. Those who assessed their body weight as too high performed almost half as many tasks $(\mathrm{M}=50$; $\mathrm{SD}=35.05)$ as individuals who assessed their body weight as normal $(\mathrm{M}=95.58 ; \mathrm{SD}=95.19)$. Differences in time spent on the whole tasks were at the level of trend $(p=0.058)$ and indicated that people who assessed their body weight as normal spent much more time on the tasks. For these comparisons, Cohen's d was in the range of 0.54-0.67. The observed effect size was classed as a medium. ${ }^{26}$ Almost one third of the subjects, despite having normal body weight, assessed it as too high and achieved weaker results in the analyzed indicators of perseverance than the subjects who assessed their body weight as normal. Differences in the number of tasks performed and the average time of work on a single task were statistically significant $(p<0.05)$.

\section{Perseverance as a function of subjective assessment of body weight of subjects with BMI above normal}

The subjects with higher BMI values (overweight and obesity) were compared depending on the subjective assessment of body weight, therefore differing significantly in the number of tasks performed and the total time spent on the task. The results in the group with BMI above normal are presented in Table 4. In both the groups with normal and with higher BMI values, these indices were higher for people who assessed their body weight as normal. Individuals with BMI above normal, but assessing their body weight as normal, spent significantly less time on one task $(\mathrm{M}=7.57 ; \mathrm{SD}=0.97)$ in comparison to those with higher BMI values and at the same time assessing one's one body weight as too high $(\mathrm{M}=20.33$; $\mathrm{SD}=22.89$ ). For these comparisons, Cohen's $d$ was in the range of $0.79-1.17$. The observed effect size was classed as large and was the largest of the examined groups. ${ }^{26}$ 

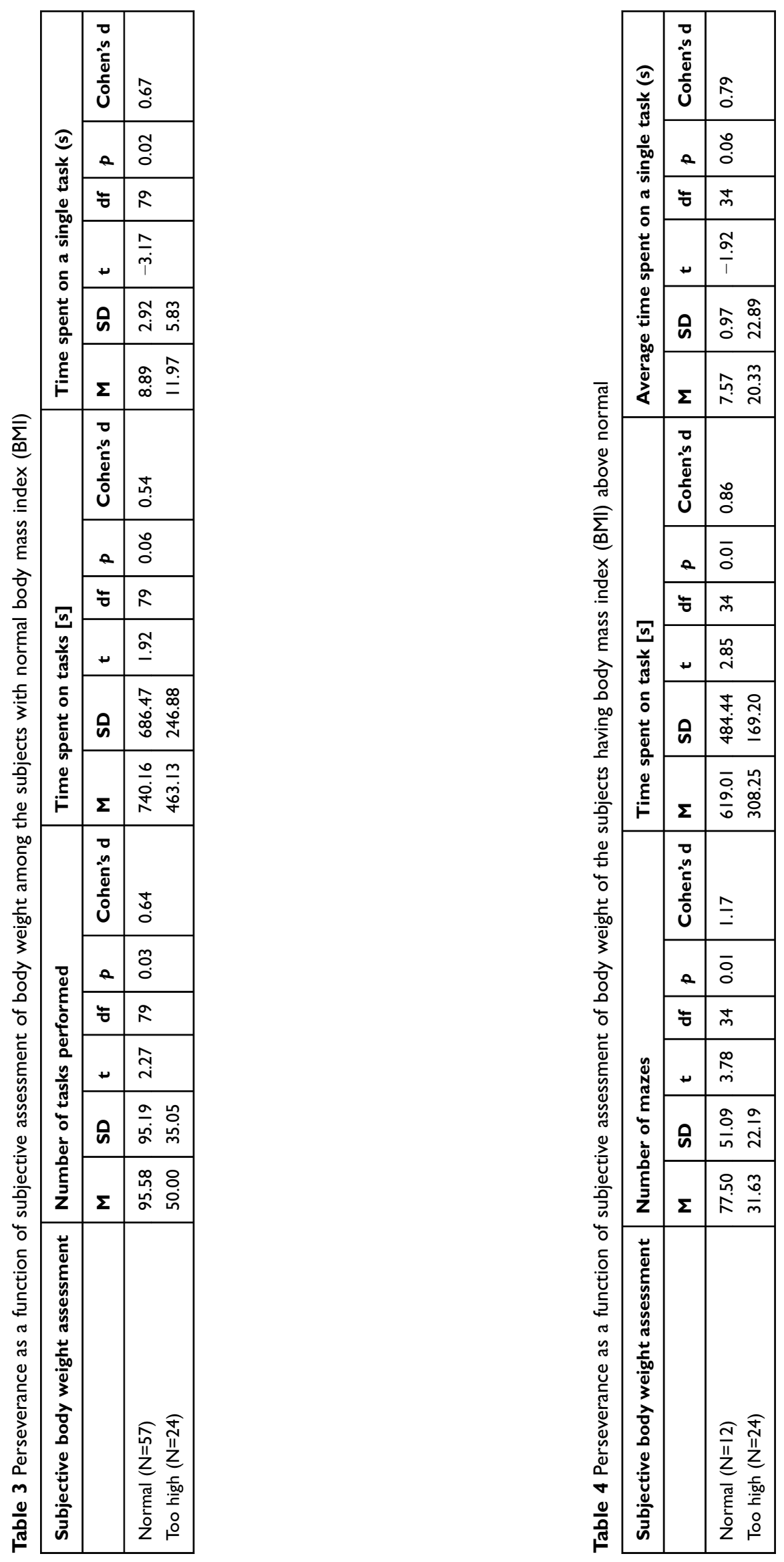


\section{Discussion}

Excessive body weight may lead to a reduction in the quality of life due to medical, economic, social and psychological consequences. The latter include depression and mood disorders, reduced self-efficacy, negative emotions, negative body image, fixation on food and nutrition, increased levels of aggression and sexual dysfunctions. $^{27,28}$

The study showed differences in perseverance between groups of people with normaland higher body weight. Perseverance rates in the form of the number of tasks performed and the time spent on the task were significantly higher in the group of people with normal BMI. The third analyzed indicator, the average time of completing one task, was significantly lower in the group with normal BMI than in the group with overweight and obese people.

Therefore, it can be concluded that the subjects with normal body weight performed tasks more persistently (number of tasks performed and time spent on tasks) than people who are overweight. Moreover, individuals with normal body weight better managed distractors (average time of performing a single task), which could distract them from the task being performed.

Mobbs et al in their research found that low perseverance in obese and overweight people is associated mainly with difficulties in stopping irrelevant thoughts or memories. ${ }^{3}$ In our study, there was a positive correlation of BMI with the average time spent on a single task, but this was a negligible correlation.

Analyzing the subjects in terms of their body image revealed a similar tendency as in the analysis of data based on BMI. Indicators of perseverance (number of tasks and time spent on a task) were lower in group perceiving their body weight as too high (similarly as in groups of those who were actually overweight). The average time of performing a single task was higher in group assessing their body weight as too high than in the group assessing their body weight as normal. It can, therefore, be concluded that those who assessed their body weight as too high performed the tasks not only less persistently but also their resistance to distractors was smaller.

The subjects, regardless of whether they assessed their body weight as too high or not, who actually had BMI indicating overweight or obesity were characterized by possessing less perseverance in performing the tasks. The weaker ability to focus on the task could also result in the smaller number of maze tasks completed.

When analyzing subjects with higher BMI values, significant differences were demonstrated in the number of tasks performed and the time spent on the tasks. The subjects classed as overweight who assessed their body weight as too high needed almost three times as much time to perform one task than the overweight subjects who assessed their body weight as normal. The observed difference was on the level of the trend. These differences indicated better perseverance of people assessing their body weight as normal regardless of whether it is actually normal.

The analyzed data indicated that having a negative body image is associated with lower values of perseverance; however, the effect size of these relationships was not the same. In the group with overweight and obese people, the effect size of observed indicators was stronger than those with a normal weight.

Dissatisfaction of one's body image is related to weight self-stigma. ${ }^{14}$ Negative body image can be associated with poor psychological functioning, e.g. low persistence. Studies to characterize overweight and obese people show that people with excessive body weight are characterized by lower self-esteem and lower self-efficacy. ${ }^{14,29}$ Social discrimination and stereotypes about overweight and obese people could create beliefs in these people that they are lazy and not persistent. $^{12,14,15}$ Weaker perseverance in the group of obese patients may be related to these stereotypes. Individuals can internalize these stereotypes and hold weight-related stigma and self-esteem devaluation. The influence of stereotypes and discrimination on overweight people is very strong. ${ }^{30}$ This negative stigma could also affect people who have the correct body mass, but their subjective body image is negative. The effect size of this dependence is lower than in the group with overweight people, but it is very important and indicates the possibility of how strong influence could have stereotypes.

Perseverance deficits may affect, amongst other things, the problems associated with maintaining a correct and healthy diet, which in turn can increase body weight and lead to overweight and obesity. Obesity and overweight, in turn, can build a negative body image. ${ }^{11,31}$ Therefore, it cannot be ruled out that overweight and obese people may experience a kind of feedback loop that increases perseverance deficits along with a negative 
image of their own bodies. As a consequence, these perseverance deficits can lead to problems with maintaining the diet, which may result in an increase in body weight and further deepen the negative body image.

\section{Clinical implications}

The described relationships can be used for psychological support and assistance to overweight and obese people. They can also be widely used in the prevention of eating disorders. When working with people who are overweight or obese, attention should be first paid to their subjective perception of their bodies and weight self-stigma. It is also important to keep in mind the harmful stereotypes, social discrimination and their negative impact on overweight people. It is worth implementing educational programs to prevent the emergence of negative stereotypes regarding obese people. Further, implementation of therapies aimed at improving self-esteem overweight and obese people can help increase perseverance, which is an important factor in the treatment.

\section{Limitations}

It should be emphasized that in our research, the weight and height of participants were declared by themselves. Therefore, the determination of these parameters, including BMI, could have been distorted. To eliminate abnormalities in the assessment of the correctness of body weight in subsequent studies, it is necessary to exclude declaring the height and weight of one's body by replacing the declaration with the measurement of height and weight in the subjects by the researchers. In the next step, when selecting the study group, it would be advisable to exclude people with possible metabolic disorders and to distinguish the group of people with body image disorders. The perseverance and goal achievement are undoubtedly related to the resources, health and psychological condition of individuals. ${ }^{32-34}$ Studies on the co-occurrence of depressive symptoms and depressed mood with BMI indicate the U-shaped relationship of these variables. ${ }^{7}$ In people having a BMI either below or above the norm, depressive symptoms were more frequent than amongst people with normal BMI. The study did not consider factors associated with depression and depressed mood. It is advisable to consider this factor in further studies.

\section{Conclusions}

This study has shown that perseverance is associated with body image. There was a positive correlation between the distractor resistance index and BMI.

The individuals with higher than normal BMI range solved fewer maze tasks and dedicated a shorter time for whole tasks. The average time spent on a single task was longer in this group in comparison to people with normal BMI.

Lower results of analyzed perseverance indexes were observed in people perceiving their body weight as too high regardless of the BMI values. The effect size of this relationship was classed as medium in the group with normal BMI and large in the BMI group over the norm.

These relationships may form the basis for further research on perseverance and diseases associated with overweight and obesity. Attempts should also be made to investigate perseverance rates in a group of people with weight below normal. Future analysis is necessary to better understand the relationship of body image with perseverance.

\section{Availability of data and materials}

The datasets used and/or analyzed during the current study are available from the corresponding author on reasonable request.

\section{Acknowledgment}

Special thanks are due to Christiana Lucas and Georgia Lucas for proofreading and editing assistance, as well as substantive verification.

\section{Author contributions}

WS designed conception of the work, carried out research, prepared statistical analysis, interpreted the results and provided approval for the publication of the content. SZ analyzed medical data, interpreted the results and revised critically the content of the work. WK analyzed psychometric data, checked the correctness of the analysis of these data and provided approval for the publication of the content. All authors contributed to data analysis, drafting or revising the article, gave final approval of the version to be published and agreed to be accountable for all aspects of the work.

\section{Disclosure}

The authors report no conflicts of interest in this work. 


\section{References}

1. Pozza C, Isidori AM. What's behind the obesity epidemic. In: Laghi A, Rengo M, editors. Imaging in Bariatric Surgery. Cham: Springer International Publishing; 2018:1-8. doi:10.1007/978-3-319-49299-5_1

2. Nederkoorn C, Braet C, Van Eijs Y, Tanghe A, Jansen A. Why obese children cannot resist food: the role of impulsivity. Eat Behav. 2006;7 (4):315-322. doi:10.1016/j.eatbeh.2005.11.005

3. Mobbs O, Crépin C, Thiéry C, Golay A, Van der Linden M. Obesity and the four facets of impulsivity. Patient Educ Couns. 2010;79 (3):372-377. doi:10.1016/j.pec.2010.03.003

4. Radziwiłłowicz W, Macias M. Original article self-esteem and achievement motivation level in overweight and obese adolescents. Heal Psychol Rep. 2014;2:132-143. doi:10.5114/hpr.2014.43920

5. McElroy SL, Kotwal R, Malhotra S, Nelson EB, Keck PE, Nemeroff CB. Are mood disorders and obesity related? A review for the mental health professional. J Clin Psychiatry. 2004;65(5):634-651, quiz 730. Available from: http://www.ncbi.nlm.nih.gov/pubmed/15163249.

6. Faith MS, Matz PE, Jorge MA. Obesity-depression associations in the population. J Psychosom Res. 2002;53(4):935-942. Available from: http://www.ncbi.nlm.nih.gov/pubmed/12377306.

7. De Wit LM, Van Straten A, Van Herten M, Penninx BW, Cuijpers P. Depression and body mass index, a u-shaped association. $B M C$ Public Health. 2009;9:1-6. doi:10.1186/1471-2458-9-14

8. Braet C, Claus L, Goossens L, Moens E, Van Vlierberghe L, Soetens B. Differences in eating style between overweight and normal-weight youngsters. J Health Psychol. 2008;13(6):733-743. doi:10.1177/ 1359105308093850

9. Engel SG, Robinson MD, Wonderlich SJ, et al. Does the avoidance of body and shape concerns reinforce eating disordered attitudes? Evidence from a manipulation study. Eat Behav. 2006;7(4):368374. doi:10.1016/j.eatbeh.2005.12.002

10. Pellizzer ML, Waller G, Wade TD. Body image flexibility: a predictor and moderator of outcome in transdiagnostic outpatient eating disorder treatment. Int J Eat Disord. 2018;51(4):368-372. doi:10.1002/eat.22842

11. Hrabosky JI, Cash TF, Veale D, et al. Multidimensional body image comparisons among patients with eating disorders, body dysmorphic disorder, and clinical controls: a multisite study. Body Image. 2009;6 (3):155-163. doi:10.1016/j.bodyim.2009.03.001

12. JD L, AJ S, GT W. Stigmatized students: age, sex, and ethnicity effects in the stigmatization of obesity. Obes Res. 2005;13(7):12261231. doi:10.1038/oby.2005.145

13. Lillis J, Luoma JB, Levin ME, Hayes SC. Measuring weight selfstigma: the weight self-stigma questionnaire. Obesity. 2010;18 (5):971-976. doi:10.1038/oby.2009.353

14. Wott CB, Carels RA. Overt weight stigma, psychological distress and weight loss treatment outcomes. J Health Psychol. 2010;15(4):608614. doi:10.1177/1359105309355339

15. Jauregui-Lobera I, Bolanos Rios P, Santiago-Fernandez MJ, GarridoCasals O, Sánchez E. Perception of weight and psychological variables in a sample of Spanish adolescents. Diabetes Metab Syndr Obes Targets Ther. 2011;4:245. doi:10.2147/dmso.s21009

16. Marszał-Wiśniewska M, Jarczewska-Gerc E. Self-control in weight loss process. In: Lobera IJ. editor. Weight Loss. London: IntechOpen Limited;2018:13-40. doi:10.5772/intechopen.76127
17. Marszał-Wiśniewska M, Jarczewska-Gerc E. Role of mental simulations in the weight loss process. $J$ Psychol Interdiscip Appl. 2016;150 (1):1-14. doi:10.1080/00223980.2014.987102

18. Styk W, Iskra J, Klinkosz W. Mental simulations in people with normal body mass and overweight. Sci Bull Chelm Sect Pedagog. 2018;2:111-121.

19. Styk W, Kozinska-Lipinska M Wytrwałość i Osiagnie Celów. Rola Ukierunkowanych Myśli i Symulatywności Mentalnej. [Perseverance and achieve goals. The role of targeted thoughts and mental simulation]. Create Succesfull Ideas; 2018.

20. Datu JAD, Valdez JPM, King RB. Perseverance counts but consistency does not! Validating the short grit scale in a collectivist setting. Curr Psychol. 2016. doi:10.1007/s12144-015-9374-2

21. Lukaszewski W, Jarczewska-Gerc E. Mental simulation and persistence in action. J Russ East Eur Psychol. 2012. doi:10.2753/ RPO1061-0405500302

22. Welker KM, Carré JM. Individual differences in testosterone predict persistence in men. Eur J Pers. 2015. doi:10.1002/per.1958

23. Body mass index - BMI. Available from: http://www.euro.who.int/en/ health-topics/disease-prevention/nutrition/a-healthy-lifestyle/bodymass-index-bmi. Published 2019.

24. Cash TF, Fleming EC. The impact of body image experiences: development of the body image quality of life inventory. Int $J$ Eat Disord. 2002;31(4):455-460. doi:10.1002/eat.10033

25. Stice E, Shaw HE. Role of body dissatisfaction in the onset and maintenance of eating pathology: a synthesis of research findings. $J$ Psychosom Res. 2002;53(5):985-993. Available from: http://www. ncbi.nlm.nih.gov/pubmed/12445588.

26. Sawilowsky SS. New effect size rules of thumb. J Mod Appl Stat Methods. 2009;8(2):597-599. doi:10.22237/jmasm/1257035100

27. Brandt HA, Crawford SF. Eating disorders 2018: new insights in diagnosis, research, and treatment. Psychiatr Clin North Am. 2019;42(1):xiii-Xv. doi:10.1016/j.psc.2018.11.001

28. Mashalpourfard M. Relationship of social anxiety, body image perception and depression with bulimia nervosa and anorexia nervosa in youth. J Fundam Ment Heal. 2018;20(2):138-147.

29. Rankin J, Matthews L, Cobley S, et al. Psychological consequences of childhood obesity: psychiatric comorbidity and prevention. Adolesc Health Med Ther. 2016;7:125-146. doi:10.2147/AHMT.S101631

30. Wang SS, Brownell KD, Wadden TA. The influence of the stigma of obesity on overweight individuals. Int J Obes. 2004;28(10):13331337. doi:10.1038/sj.ijo.0802730

31. Hurst M, Dittmar H, Banerjee R, Bond R. "I just feel so guilty": the role of introjected regulation in linking appearance goals for exercise with women's body image. Body Image. 2017;20:120-129. doi:10.1016/j.bodyim.2016.12.002

32. Olson K, Bond D, Wing RR. Behavioral approaches to the treatment of obesity. In: handbook of obesity: clinical applications. $R$ I Med J. 2017; March:21-24.

33. Bhanji JP, Kim ES, Delgado MR. Perceived control alters the effect of acute stress on persistence. J Exp Psychol Gen. 2016;145(3):356365. doi:10.1037/xge 0000137

34. Lunenburg F. Goal-setting theory of motivation. Int J Manage Bus Adm. 2011;15(1):1-6. 


\section{Publish your work in this journal}

Psychology Research and Behavior Management is an international, peer-reviewed, open access journal focusing on the science of psychology and its application in behavior management to develop improved outcomes in the clinical, educational, sports and business arenas. Specific topics covered in the journal include: Neuroscience, memory and decision making; Behavior modification and management; Clinical applications; Business and sports performance management; Social and developmental studies; Animal studies. The manuscript management system is completely online and includes a very quick and fair peer-review system, which is all easy to use. Visit http://www. dovepress.com/testimonials.php to read real quotes from published authors. 